\title{
Thin-Film Module Reverse-Bias Breakdown Sites Identified by Thermal Imaging
}

Steve Johnston ${ }^{1}$, Dana Sulas ${ }^{1}$, Elizabeth Palmiotti ${ }^{2}$, Andreas Gerber ${ }^{3}$, Harvey Guthrey ${ }^{1}$, Jun Liu ${ }^{1}$, Lorelle Mansfield ${ }^{1}$,

Timothy J. Silverman ${ }^{1}$, Angus Rockett ${ }^{2}$, and Mowafak Al-Jassim ${ }^{1}$

${ }^{1}$ National Renewable Energy Laboratory, Golden, CO, 80401, U.S.A.

${ }^{2}$ Colorado School of Mines, Golden, CO, 80401, U.S.A.

${ }^{3}$ IEK5-Photovoltaics, Forschungszentrum Jülich $\mathrm{GmbH}$, Jülich, 52425, Germany

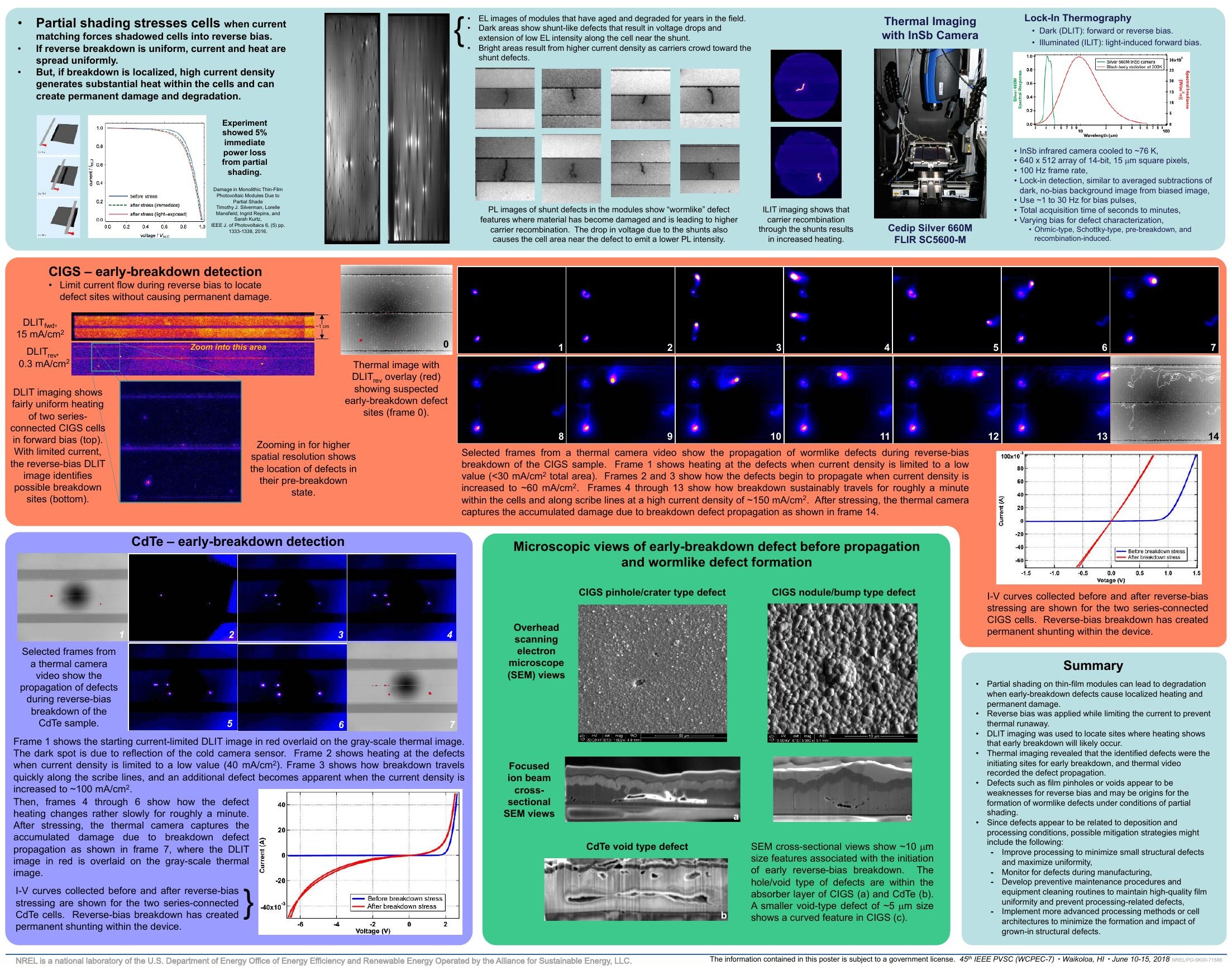

